\title{
RELATIONSHIP AMONG LOCUS OF CONTROL, PERSONALITY AND ACADEMIC ACH! EVEMENT OF SECONDARY SCHOOL STUDENTS IN SOKOTO METROFOLIS
}

HALIRU SADIYA MAGAJI

\begin{abstract}
The main purpose of this study was to determine the relationship among locus of control. personality and academic achievements of senior secondary Students in Sokoto metroplis. The samples were drawn from a toral of 360 students in seven senior secondary schools purposively selected in Sokoto metropolis. For this study, adopted version of Olumolave's self-other motivation scale, adopted version of Akimboye's subscale $A$ of adolescent personal data inventory and students' JS III examination results of English. Mathematics, Integrated science and Social studies to measure the variables of locus of control. personality and academic achievements. Four hypotheses were generated and tested in this study. Multiple regression analysis and Pearson product moment correlation coefficient were used to analyze data collected. Result of the study shoved that, there exist significant relationship among locus of control, personality and academic achievement, a significant relationship exist between personality of students and their academic achievement. One the recommendations of this study, is that teachers and counsellors should attempt to handle students individually as students vary on locus of control scale and personality.
\end{abstract}

\section{INTRODUCTON}

There have been great achievers in almost every field of endeavour, who derived their success primarily from great qualities of character. There are others, who have exceptional motor skills, and in a number of instances there are men and women who have been blessed with both qualities and who have become legendary figures in their particular field (Hashman \& Jonas, 1977). The later assertion seems to be a pointer to the fact that many factors make up an achiever.

Some children are identified as exceptional because they have set of normal attributes to an exceptional degree. Children labeled intellectually gifted or mentally retarded are thus identified because they are considered to have much more or much less of an attribute that all humans have. Spodeck.
(1978) seems to indicate that every individual is composed of different intellectual ability, and that intelligence is an extension of biological adoption consisting of the processes of assimilation (processes responsive to inner prompting) and of accommodation (processes responsive to environmental intrusions).

That some children have physical and intellectual abilities especially well adopted for successful performance in certain tests may be readily verified by observation. Maureen and Harris (1983) working on locus of control and academic achievement concluded that beliefs ill internal reinforcement are associated with greater academic achievement, and that the relation tended to be stronger for adolescents than for adults or children, and more substantial among males than among females. Cunningham (1927). in his studies on 
several kinds of gross motor tasks, found that performance of the school children depended more on body-build (personality) than on instruction or verbal ability. It can therefore be said that academic achievement can be positively influenced by a person's personality and personal control (locus of control belief). Thus there are therefore desirable personality and personal control for optimum academic achievement which may vary from discipline to discipline.

The word personality has a variety of meanings and is interpreted in different perspectives under different circumstances. However, Guilford (1959), Eysenck (1965), Lovell (1981), Adana and Ndalolo (1990) have all observed that personality is a broad term to include all of an individual's traits, his/her physical characteristics, intellectual qualities, aptitudes and talents, as well as his temperamental qualities, interests, expressive behaviour and pathological symptoms.

Ndalolo (1990), opined that personality is grouped into two - extroversion and introversion. Eysenck (1965) noted that the extrovert is a sociable and outward person who takes risks and chances easily. He is impulsive with ready answers. He is carefree, optimistic and like changes. While the introvert, according to Eysenck (1965) is a quiet retiring sort of person who is introspective and is fond of books rather than peoples. He/she is reliable, somewhat pessimistic. $\mathrm{He} / \mathrm{she}$ tends to plan ahead, looks before he/she leaps. The introvert is noted by Eysenck (1965) to be most interested in his/her own thoughts; and is seen to be generally more studious, more efficient and predisposed towards scientific achievement. From the foregoing, if academic achievement is to be judged by input, one would want to accept that there could be high correlation between high academic achievement and introversion, and low correlation of academic achievement with extroversion.

The concept "locus of control" is described by Asonibare (1985) as a cognitive style with which a person consistently approaches his environment in attributing pay-offs. Asonibare, (1986) viewed locus of control as a motivational and attitudinal variable strongly affecting achievement. Bartel (1971) has documented that children enter school not measurably different from one another in locus of control, but by the time they reach the sixth grade, they are significantly different from one another on this characteristics. What is therefore the trend of the secondary school students on the locus of control scale? Assuming from the above, one would want to accept that there is the need to provide data on the trend of Nigerian Students on the locus of control measure. It is the hope of this study to pay particular attention to this, and the differences that could abound in the way it relates to personality and academic achievement. A study by Cooper, (1981) reported a positive correlation between locus of control and academic achievement and that children who take more responsibility for academic tend to do better in school.

It is believed that no two individuals are the same, there must be some differences in either behaviour, aptitude, talents or physical appearance. The locus of control and personality of any individual 
is therefore distinct from another as such his individuality is $\mathrm{me}$ asured with such factors which do influence his relations with other people and also influence his academic performances. Many failures in schools have been explained by many scholars from different points of view such as factors within the school, within the family and within the child. Some scholars have tackled factors within the child from the child's self concept point of view. Success/failure in work situations is to a large extent a matter of personal characteristic of the child.

Parents and educational administrators however use certain parameters to judge the success or otherwise of students in schools; some attributes it to teachers, others to facilities in the school etc. While these arguments continue, certain psychological reasons need to be explored to ascertain precise by the reasons behind such failures. Issues like personality and locus of control as they affect academic achievement.

This study was instituted to examine how far locus of control, personality and academic achievement is related to the child's personality or his/her locus of control.

\section{Research Hypotheses}

In addition to attempting to answer the research question on relationship among secondary school students in Sokoto north and south local government areas of Sokoto state on the locus of control and personality , Academic Achievement the following hypotheses were tested.

1. There is no significant relationship among. locus of control, personality and academic achievement of students of secondary school in Sokoto metropolis of Sokoto state.

2. There is no significant relationship between the locus of control and academic achievement of students of secondary school in Sokoto metropolis of Sokoto state.

3. There is no significant relationship between the personality and academic achievement of students of secondary school in Sokoto metropolis of Sokoto state.

4. There is no significant relationship between locus of control and personality of students of secondary school in Sokoto metropolis of Sokoto state.

\section{Research Design}

This researcher used a descriptive survey design. It was aimed at finding out the relationship among locus of control, personality and academic achievement of secondary school students in Sokoto metropolis.

\section{Population of the Study}

The population of this study included all the 42 secondary schools in Sokoto metropolis. Out of which 20 are Sokoto state owned, two are Federal Government owned and five are private senior secondary schools. While fifteen are Sokoto State Government controlled junior Secondary Schools which are excluded from the study because they have not yet written the junior secondary 
school examination to be used for the study.

A total of 6,635 students are found in SS 1 of the 25 senior secondary schools including the two federal Government colleges and three private schools.

\section{Samples and Sampling Techniques}

The sample for study was selected from senior secondary school classes (SS 1) students using simple random sampling techniques. However, for convenience of the researcher, due to time and financial constraint, seven secondary schools owned by the Sokoto state Government were selected for this study. A total of 6.535 students are found in SS 1 of the
25 senior secondary schools including the two federal Government colleges and three private schools.

On the whole, a total of three hundred and sixty (360) students sample were selected for the study from seven senior secondary schools.. Both sexes were eligible for inclusion in the study. Senior Secondary class three students (SS III) were exempted as they will be preparing for the final Senior Secondary School Certificate Examination. In addition. Junior Secondary class students were equally exempted as they are yet to attempt the Junior Secondary final certificate examination which was used to measure academic achievement.

Table 1: $\quad$ List of Schools sampled

\begin{tabular}{|c|c|c|c|c|c|}
\hline S/No & Name of Schoo & & $\begin{array}{l}\text { Total Number in } \\
\text { Class SS (One) }\end{array}$ & No. Sampled & \\
\hline 1. & Ahmadu Bello & Academy & 100 & 50 & \\
\hline 2. & G T C Farfaru & & 80 & 40 & \\
\hline 3. & HABMAS & & 120 & 60 & \\
\hline 4. & NGSS & & 80 & 40 & \\
\hline 5. & GAMGMC & . & 80 & 40 & \\
\hline 6. & GDSS Arikilla & & 100 & 50 & \\
\hline 7. & GGC & & 80 & 40 & \\
\hline & TOTAL & & 640 & 360 & \\
\hline
\end{tabular}

\section{Instrument for data collection}

To measure locus of control and personality, two different questionnaires were used to elicit such information from the respondents; while data on academic achievement were collected from the school records of students, scores in the junior secondary final examination. conducted by the Sokoto State Ministry of Education, Sokoto. The two main questionnaires are:
1. The adapted version of Folusho Olomolaiye's self- other motivation scale Adopted from Tambuwal (2000), was used to measure Locus of Control of respondents.

2. The Adapted version of Akinboye's sub-scale A of the adolescent personal data inventory (APDI) adopted from Tambuwal (2000) was used to measure the personality of students. 


\section{Measure of Academic Achievement}

The data on Academic Achievement was collected from the school records of students scores in the J.S. III final examination, conducted by the Sokoto State Ministry of Education. Results from the core courses - English, Mathematics, Integrated Science and Social Studies were used.

\section{Olomolaiye's (1986) Self-Other Motivation Scale.}

The self-other motivation scale, for academic Achievement is very much similar to Rotter's locus of control scale indeed, it is derived from it. The items making up this scale sought to find out the degree of confidence the individual client has in his own ability. They sought to measure the various ways the client explains what happens to him in life. Does he for example believe that he is in full control of his life or that he lives only by the benevolence of some powerful others? There are 14 paired statements in the scale: One of each pair of statements relate to the role of the individual client believes he plays in whatever happens to him while the other statement relates to the role people play in the client's achievement. The respondent is to choose which one of each pair of statements better describe his feelings and situations.

\section{Adapted Version of Olomolaiye's (1986) Self Other Motivation Scale.}

The original of Olomolaiye self-other motivation scale has 14 paired items. Tambuwal (2000) modified, and adapted the fourteen-paired items, 1 to 14 and included modified Rotter's (1986) instrument beginning from 15 to 29 .
This is because the addition gave the researcher the opportunity to tap information on many other variables that were not included in Olomolaiye's scale.

\section{Reliability}

Tambuwal (2000) using a population of 40 teachers for Abdu Gusau Polytechnic, TalataMafara (Zamfara State) and Kebbi State College Of Education, Argungu, a test re-test correlation was carried out, within an interval of four weeks between the first and second administration of the instrument. With the use of Pearson's product- moment correlation coefficient formula, a reliability coefficient of 0.88 was obtained. This was considered to be good enough for use, by Tambuwal (2000)

\section{Validity}

Tambuwal (2000) exposed the instrument to test and measurement expert/reviewers of Abdu Gusau Polytechnic, TalataMarafa and Kebbi State College of Education, Argungu to obtain an independent judgment to indicate the degree to which the test measured what it purports to measure. At the end of the exercise the test items were adjudged to possess content validity.

\section{Scoring the Self-Other Motivation Scale}

The scale is hand-scored. The statements scored are those representing a strong belief in oneself. A maximum score of 29 is possible on the scale. The response, (scores are indicated in the following scoring guide) that is, $1 \mathrm{a} 2 \mathrm{~b} 3 \mathrm{a} 4 \mathrm{a} 5 \mathrm{~b} 6 \mathrm{a}$ 7b 8a 9a 10b lla 12b 13b 14a 15a 16b 
17b 18a 19a 20b 21b 22a 23a 24b 25a 26 a 27b 28a 29a .3.4.2c.

\section{Adolescent Personal Data Inventory (APDI)}

The adolescent personal data inventory was developed by Akinboye (1985) in an attempt to develop the Course "Psychology of Nigeria Adolescents" at the Department of Guidance and Counselling, University of Ibadan. It was developed to assess some of the social, familiar, biological, personal, psychological and educational factors affecting the behaviour of Nigerian adolescents.

Similarly, the scale was developed to provide adequate knowledge about adolescents especially in the case of selection of their curriculum, education programmes.

\section{Description of Sub-Scale A Of APDI}

This section of the APDI has 30 items, which are basically the various ways an individual perceives himself. These items were generated from the products of some clinical interviews with adolescents in some Nigerian secondary schools as well as from the existing literature especially the analysis of Epstein (1973).

This sub-scale is a general selfperception scale, which taps academic, social, personal and intellectual ability perception of adolescents. This is based on the assumption that behaviour is often initiated and largely determined by selfconception. In essence, it is the view of the Author that this sub-scale may be useful in the assessment and management of a number of psychological developmental patterns in the growing child.

The Inventory can be group administered; individual and clinical administrations are possible. For the purpose of this research work, the inventory was administered to the individuals who responded. The research assistant spent some time explaining the instructions to them.

APDI is scored by the first reversing the negative items such as items 16 in subscale A (I am unreliable), If the respondent rates this 0 , then it means that he perceives himself as reliable, then the researcher reverses 0 to 5 before adding the ratings. The total score on each sub-scale of the inventory represents the construct measure by the scales.

\section{Adapted Version of the Adolescent Personal Data Inventory (APDI)}

The original version of the inventory was meant to test adolescents; as such, the researcher went through all the 30 items on the sub-scale A of the APDI and found the statements suitable for the perception of the respondents, and hence used all the thirty items.

\section{Reliability of APDI}

To obtain the reliability of the instrument, the internal consistency method was followed by Tambuwal (2000). This was done by sending the instruments to a group of lecturers of the Abdu Gusau Polytechnic and Kebbi State College of Education Argungu within a four weeks interval between the administration of the first and second test. The results of the test-re-test 
young children. Joumal of Educational Psychology, 18: 4354.

Deaux, K. \& Farris, E. (1977). Attributing causes for one's own performance: The effects of sex, norms and outcome. Journal of Research in Personality, 11: 59-72.

Ducettee, J. \& Wolk, S. (1972). Locus of control and extreme behaviour. Journal of Consulting and Clinical Psychology, 39: 253-258.

Entwistle, N. J. \& Cunningham, S. (1968). Neuroticism and school attainment - a linear relationship? British Joumal of Educational Psychology, 38: 123-132.

Eysenck, H. J. \& White, P.O. (1964). Personality and the measurement of intelligence. British Journal of Educational Psychology, 34: 197201

Fennema, E. A. \& Sherman, J. (1977). Sex-related differences in Mathematics achievement, spatial visualization and effective factors. American Educational Research, 14: $51-57$

Foster, J. \& Gade, E. (1973).Locus of control, consistency of vocational interest patterns, and academic achievement. Journal of Counselling Psychology, 20 (3): 290-292.

Guilford, J. P. (1959).Personality. New York. McGraw-Hill.

Hashman, J. \& Jones, C. M. (1977). Beginning badminton. New York. ARCO Publishing Company Inc.

Hilton, T. L. \& Berglund, G. W. (1974). Sex differences in Mathematics achievement - a longitudinal study. The Journal of Educational Research, 67: 231-237.
Jung, C. G. (1923).Psychological types. New York: Harcourt, Brace and world.

Kerlinger, F. N. (1975). Foundations of behavioural research. (2nd Ed.) New York: Holt; Reinhart and Winston Inc.

Lazarus, R. S. (1979). Personality (3rd ed.), New Jersey, Englewood Cliffs, Prentices Hall Inc.

Lefcourt, H. M. (1966). Internal versus external control of reinforcement: A review. Psychological Bulletin, 65: 206-220.

Lovell, K. (1981). Educational Psychology and children. New York: Hodder and Stoughton.

Lynn, R. \& Gordon, I. E. (1961). The relationship of neuroticism and extroversion to intellectual and educational attainment. British Journal of Educational Psychology, 31: 194203.

Maqsud, M. (1983). Relationships of locus of control to self-esteem, academic achievement and prediction of performance among Nigerian secondary school pupils. British Joumal of Educational Psychology, 53: 215-221.

Maureen, J. F. \& Harris M. C. (1983). Locus of Control and academic achievement: a literature review. Joumal of Personality and social Psychology, 44 (2): 419-427.

Ndalolo, H. A. (1990).The relationship between personality type and career decision making styles of selected Nigerian women in traditional and non-traditionalcareers in Nigeria. Unpublished Doctoral Dissertation, University of Ilorin, Ilorin. 
produced a fairly high co-efficient alpha of 0.874 .

\section{Validity of APDI}

In validating this sub scale the Tambuwal (2000) sent all the modified 30 items which scaled through the reliability test to group of lecturers of Federal College of Education (Technical) Gusau and School of Nursing and midwifery Sokoto to vet for content validation. With the unanimous agreement of the experts as to content and quality of the questionnaire.

\section{Method of data collection}

The questionnaires for this study were personally administered by the researcher along with some research assistants who were adequately trained on how to administer the APDI and SOMS questionnaires. All the respondents in each school were attended to on the same day. Respondents completed two sets of questionnaires, one after the other.

\section{Method of Analyzing Data}

The study attempted to find out the relationship between students locus of control, personality type and academic achievement. Thus, Pearson product and multiple relation regression product were used. Hypothesis one was subjected to the statistical procedure of multiple regression. Hypotheses two to four were tested by computing Pearson Product Moment Correlation co-efficient

\section{Hypotheses Testing}

The results are presented in Tables 2-5. Hypothesis 1 was tested using multiple regression analysis, hypothesis $2,3,4$ were tested using Pearson Product Moment Correlation.

\section{Hypothesis 1}

There is no significant relationship among, locus of control, personality and academic achievement of students in Sokoto metropolis of Sokoto State.

Table 2: Relationship among Locus of Control, Personality and Academic Achievement.

\begin{tabular}{lllll}
\hline Model & $\mathrm{R}$ & $\mathrm{R}$ Square & $\begin{array}{l}\text { Adjusted } \\
\text { Square }\end{array}$ & $\mathrm{R}$ \\
\hline l & $0.083^{\mathrm{a}}$ & 0.007 & 0.001 & 0.533 \\
\hline Source: & Researchers field work 2010 \\
a. Predictor (constant locus of control, personality
\end{tabular}

\section{Result}

Based on the regression results the variables of locus of control. personality explained by $83 \%$ variation in academic achievement. In essence the independent variable of locus of control, personality could predict academic achievement of the samples. 


\section{Hypothesis two:}

There is no significant relationship between the locus of control and academic achievement of students of secondary school in Sokoto metropolis of Sokoto State.

Table 3: $\quad$ Pearson Product Moment Correlation Co-efficient of Students' Locus of Control and Academic Achievement

\begin{tabular}{llllll}
\hline Variables & $\mathrm{N}$ & $\mathrm{X}$ & $\mathrm{S} . \mathrm{D}$ & Calculated $\mathrm{r}$ & $\mathrm{P}$ \\
\hline Locus of control & 360 & 61.272 & 9.201 & 0.1026 & 0.113 \\
\cline { 1 - 5 } Academic Achievement & 360 & 123.340 & 20.561 & (NS) & \\
\hline
\end{tabular}

NS = Not significant at 0.05 level.

Table 2 shows the Pearson product moment correlation co-efficient results of students' locus of control and academic achievement. The result indicates a calculated value of 0.1026 . Since the calculated $r$ value is less than the $P$ value it was concluded that there is no significant relationship between students locus of control and students academic achievement. Therefore, hypothesis two that stated no significant difference between Locus of Control and Academic Achievement of students of secondary schools in Sokoto metropolis is rejected.

\section{Hypotheses III}

There is no significant relationship between the personality and academic achievement of students in Sokoto metropolis of Sokoto State.

Table 4: $\quad$ Relationship between Personality and Academic Achievement Scores.

\begin{tabular}{l|ccccc} 
Variables & N & X & S.D & Cal r & P value \\
\cline { 1 - 4 } Personality & 360 & 25.1509 & 3.0941 & & \\
\cline { 1 - 5 } Academic & 360 & 179.2004 & 40.0047 & 32.5 & $0.1821 *$ \\
achievement & & & & &
\end{tabular}

- Significant at 0.05 level.

From the calculated Pearson Product Moment Correlation Co-efficient on personality participants scores on academic achievement scores there is an indication that, there exists a significant association between the variables. Thus we reject the hypothetical statement in favour of the alternative as well. (Thus there is significant relationship between personality and the academic achievement scores in the study at 0.05 level).

\section{Hypotheses IV}

There is no significant relationship between locus of control and personality if students in Sokoto metropolis. 
Table 5: $\quad$ Relationship Between the Locus of Control and Personality

\begin{tabular}{llllll} 
Variables & \multicolumn{1}{l}{ N } & $\mathrm{X}$ & $\mathrm{S} . \mathrm{D}$ & $\mathrm{Cal} \mathrm{r}$ & P value \\
\hline Locus of Control & 360 & 18.5000 & 0.7071 & \\
\hline Personality & 360 & 155.000 & 41.0122 & -29.00 & $-1.000 *$ \\
\hline
\end{tabular}

* Significant at 0.05 level

From the calculated Pearson Product Moment Correlation conducted, to establish if a relationship exists between scores of Locus of control of adolescents and their personality, there is indication that, there exists a perfect negative association between the locus of control of secondary school students and personality.

The calculated $P$ value $(-1.000)$ indicates that the imperfect correlation is indirectly (inversely) and not a direct association. Hence we reject the hypothetical statement that states that there is significant relationship between Locus of Control and Personality of students.

\section{Discussion of Findings}

The rejection of hypothesis one suggests that a significant relationship existed among locus of control, personality and academic achievement of students in Sokoto metropolis. The rejection however confirms the long standing opinion and findings of Rotter (1966) Foster and Gade (1973), Maureen and Harris (1983) who found that a positive relationship exists between locus of control and academic achievement, personality and academic achievement, and that the relationship is logically and intuitively appealing.

In a closely related study. Phares (1976) cited by Maureen and Harris (1983). examined the link between locus of control and achievement in children. Most of the studies reviewed by Phrase (1976) used the Intellectual Achievement Responsibility (IAR) Scale (Crandall, Katkovsky\& Crandall, 1965) as the locus of control measure and grades or standardized test scores as indices of academic achievement. Phares (1976) thus concluded not only that positive oriented locus of control children showed superior academic performance but that this relation might be more substantial in children than in adults. This position is strengthened by Maureen and Harris (1983) who about a decade after Foster and Gades (1973) findings revealed that a positive relation between locus of control and achievement is logical and intuitively appealing. Working on locus of control and academic achievement, Maureen and Harris (1983) concluded that locus of control and academic achievements are significantly positively related, and that the magnitude of the relation is small to medium, but the relation may hold substantial practical or explanatory significance relative to other explanations of the two variables. Also, it has been observed by Bar-Tal and BarZohar (1977) that there exists a firm trend in the perception of the relationship between locus of control and academic achievement.

In addition. the finding of locus of control as the better predictor of 
academic achievement as compared to personality type also supports the study by Asonibare (1985) whose findings indicate that locus of control is a motivational variable that strongly affect achievement. Maureen and Harris (1983) had also associated locus of control with behaviours that affect the probability of attaining success.

Nevertheless. from the analysis shown, personality was found to be a poor predictor of academic achievement. A synopsis of this revelation indicates that locus of control and personality are terms that may not be interchangeably used as far as academic achievement is concerned. However if locus of control and personality were to be interchangeably used, then such a very low correlation (.001) got in respect of personality and academic achievement should not be expected. People are said to have certain personality characteristics or belong to personality group when they are observed by others or themselves to behave in predictably similar ways over varied events and situations.

The results of hypotheses two revealed significant relationship between locus of control and academic achievement. The rejection of the null hypothesis is supportive of Ducettee and Wolk (1972), Phares (1976), Maureen and Harris (1983) who among others believed that the locus of control of students (and/do) react differently to academic achievement tasks. A perusal examination of the result revealed that the levels of academic achievement revealed a coefficient of 0.1130 a high means of standard deviation which is an indication of reaction to locus of control by academic achievement This also confirms an earlier asserted statement in the literature, that behavioural differences are demonstrated between subjects falling at various point along the locus of control dimension. However, this finding confirms the findings of Maqsud (1983), Maureen and Harris (1983) who earlier found, among other things that locus of control had significant positive relationship with the academic achievement.

From the above, one would observe that the trend of the relationship between locus of control and achievement is significantly positive irrespective of the instruments used to collect data. Looking at the relation between locus of control and academic achievement from the motivational point of view, Cooper, Jerry \& Thomas, (1981) concluded that persons high in the need to achieve also hold a strong belief that efforts and outcomes covary. High achievers were noted to believe most strongly that hard work pays off, and that such locus of control must be present before a person will try to achieve. Rotter (1966) had earlier documented that individuals with positive locus of control would engage themselves more in achievement related activities than negative locus of control who tend to feel that they have little control over their rewards and punishments.

The result of the third hypotheses revealed that no significant relationship exists between the personality and academic achievement of students at 0.05 level of significance. The acceptance of the null hypotheses however negates the submission of Spector (1983) who noted that personality may affect behaviour, and the consequences of behaviour may in 
turn affect personalit'. However, from contradiction obtained from this present study and past studies, it may be logical to submit that personality a psychological variable may not be interchangeably with other related variables like locus of control. Both were however noted to be motivational and attitudinal variable strongly affecting academic achievement as noted above. This is likely to have emanated from the fact that the degree to which each variable affects academic achievement differs.

Astington (1960) in his studies on personality assessment and academic performance in a boys' grammar school, using a questionnaire for appraising intro-version-extraversion and teachers rating for academic achievement, found an average correlation of 0.60 , between the two variables (personality and achievement). In his study of individual and group differences in behaviour processes, Biggs (1978) also found a positive relationship between personality and environmental factors via academic performance. In another study on the contribution of student personality type and temperament to performance and satisfaction in school, using a sample of 133 high school students aged $15-17$ years, Paisey and Paisey (1982) found a significant relationship between student grades in class and Eysenck Personality Questionnaire (Eysenck \& Wilson, 1975).

Eysenck and Cookson (1969) using 4,000 eleven year old boys and girls on the Junior Eysenck Personality Inventory, analysing it in relation to performance on scholastic and ability tests, at the primary school leaving age, found that negative locus of control boys and girls are scholastically superior to positive ones. The relations they noted to be linear on the whole and may be expressed by a product moment correlation coefficient of 0.20 or there about. These findings however negates an earlier one from Entwistle and Cunningham (1968) who used 1,472 girls and 1,523 boys all aged 13 found extraverted girls and positive locus of control boys to be more successful in school work than children with opposite personality characteristics. An overall negative linear correlation of -0.2 was established between negative locus of control and school achievement for both sexes. Eysenck and White (1964) also in an earlier study have suggested that the low values of the correlation coefficients between personality and intellectual measures in many studies might be caused by a non- linearity of relationship. Similar to that found by Lynn and Gordon (1961). In the same presentation, Eysenck and White (1964) went further to suggest that children of different personality may also have different personality and intellectual structures.

From the above findings, one may not find it difficult to establish the differential influence of age and sex on personality and achievement which has resulted into the discrepancies as per the findings. Eysenck and Cookson (1969), Entwistle and Cunningham (1968) have among others revealed that negativism is generally positively correlated with academic achievement among young school children but negatively correlated among older pupils and students. The study therefore suggests that academic achievement at the primary school level may be linked to negativism, but that the picture gradually changes during the 
secondary school years so that by the time higher education is reached positives are favoured. Many psychologists (Hilton \& Berglund, 1974, Fennema \& Sherma, 1977) have also argued that the changes may be explained in terms of role, expectation and interest. However, others like Seward and Seward (1980) have also suggested the changes to be traced to physiological origin. Eysenck (1967) has documented that the position of an individual on the positive-negative continuum of locus of control is thought to reflect the level of physiological arousal of the brain. This physiological characteristic is explained to affect both social and cognitive behaviour, indicating that socially high arousal is. associated with positivism while low is associated with negativism. The acceptance of hypotheses four, from the result of Pearson Moment coefficient value as compared to personality with a value of -1.000 The principle of homogeneity suggests that an indirect association existing indirectly. Common purpose and characteristics looked into in this present study is academic achievement, which has revealed no commonality between the two main groups (locus of control and personality).

A study by Jung (1923) reported that the negative locus of control is dominated by positive and social reality, the positive on the other hand is said to approach the world subjectively in terms of its relevance to himself/herself. This view is supported by Lazarus (1979) who also documented that the flow of energy in the positive is toward the inner, subjective world, and energy in the negatives is towards the outer objective world on locus of control parameter, Maureen and Harris (1983) have also described the positive as people who feel personally responsible for the things that happen to them. Negative on the other hand are people who feel that their outcomes in life are determined by forces beyond their control (for example fate, luck and other people). Extending this line of reasoning to personality, one would want to speculate that locus of control orientations may be associated with personality. Presumably, positive would be positively associated with positivism while negatives would also be positively associated with negativism vis-a-vis their academic achievement.

Similarly, Spector (1982) has noted that locus of control may affect behaviour, and the consequences of behaviour may in turn affect locus of control. Lazarus (1979) had earlier described locus of control as a personality dispositions that is often looked upon as a relatively stable personality characteristics.

\section{Conclusion}

From the discussion and the findings of the study, the following conclusions are drawn:

- That locus of control, personality and academic achievement are positively related

- That locus of control is a better predictor of academic achievement than personality in the study. The discovery that locus of control and personality can influence academic achievement is an indication that locus of control is a motivational variable that strongly affect academic achievement 
The insignificant interaction effect between personality type and locus of control was unexpected and thus revealed that both variables cannot be inter-changeably used. but are joint motivational and attitudinal variables affecting academic achievement.

\section{Recommendations}

Although the findings reported in this study are by no means conclusive, they do suggest the need for teachers and counsellors to pay attention to handling students individually, as students vary on locus of control scale and personality groupings.

Test and non-test techniques equipment for the identification of children in the various categories should be made available in our schools.

Students who are found to have negative locus of control should be helped by the school guidance and counselling section to solve their problems on their own and be led through decision making theories on how to make independent decision.

A deliberate policy should be put in place by the Sokoto state government for the establishment of full fledged and functional guidance and counselling centres in secondary schools in the state.

\section{References}

Abiri, O. O. (1966). The educational attitudes of some Nigerian adolescents grammar school pupils. West African Journal of Edication, 1 (3): 118- 121
Adana, B. S. (1986). Job finding. In T. Olpaye (Ed), Educational and vocational guidance: Concepts and approaches. lle-Ife: University of Ife Press Ltd.

Ahmed, B. (1991). The relationship between personality characteristics and attitude towards death and dying among University of Ilorin students. Unpublished M.Ed. proposal. University of Ilorin.

Asonibare, J. B. (1986). Personal control and religious differences in selected secondary schools students in Ilorin. The Nigerian Journal of Guidance and Counseling, 2 (2): 95-102.

Bartel, N. R. (1971). Locus of control and achievement in middle and lower-class children. Child Development, 42: 1099-110 1.

Batlis, R. C. (1978). Relationship between Locus of control and students mental theory predictor of academic achievement. Psychological reports, 43: 239245,

Cattell, R. B. (1965).The scientific analysis of personality. London: Penguine

Cattell, R. B. (1973). Personality and Mood by Questionnaire. London: Jossey-Babs, Inc. Publishers.

Cohen, J. (1977). Statistical power analysis for the behavioural sciences. ( $\left.2^{\text {nd }} \mathrm{ed}\right)$. New York, Academic Press.

Cooper, H. M., Jerry, M. B. \& Thomas, L. O. (1981). Locus of control and academic achievements gender difference. Journal of personality and social psychology, 40 (3): 563 572.

Cunningham, B. V. (1927). An experiment in measuring gross motor development of infants and 
Phares, E. J. (1976). Locus of control in personality. Morris town, N. J.: General Learning Press.

Spector, P. E. (1982).Behaviour in organizations as a function of employee's locus of control. Psychological Bulletin. 91 (3): 482-497.

Spodeck B. (1978).Teaching in the early Years. (2nd Ed.). New Jersey: Prentice Hall, Inc. Englewood Cliffs.

Tambuwal, M. U. (2000). Relationship among self-concept, self-other motivation and career maturity of teachers in tertiary institutions in Sokoto State. Unpublished $\mathrm{PhD}$ Dissertation, Usmanu Danfodiyo University, Sokoto. 